\title{
Beyond ice: rethinking Australia's approach to illicit drugs
}

\author{
Redefining drug use as a health and social issue within a harm reduction \\ framework will require progressive policy
}

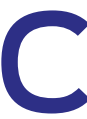

rystalline methylamphetamine ("ice") was widely discussed in Australia in 2015. At the beginning of 2016, the federal government National Ice Taskforce report ${ }^{1}$ and Prime Minister Turnbull's response to the report ${ }^{2}$ attracted substantial media attention. Twelve months on, are the report's recommendations, the funding pledged and the government's response likely to reduce the toll of ice on the Australian community?

Ice is now readily available in illicit drug markets. Drug use surveillance found that, between 2009 and 2014, the proportion of drug users finding it "easy" or "very easy" to obtain the drug increased from $65 \%$ to $91 \%$, and those reporting recent ice use increased from $37 \%$ to 61\%. ${ }^{3}$ Between 2012 and 2014, ice as a drug most commonly injected in the previous month went from $10 \%$ to $22 \%$. $^{3}$ Recent ice users had a mean age of 40 years, were more likely to be unemployed, and tended toward multiple or polydrug use. Less than half were in treatment. ${ }^{3}$ Many reported recent borrowing, lending and re-using of needles and syringes, injection injury (such as bruising or scarring), a mental health problem, and commission of a crime or arrest. ${ }^{3}$ At the same time, the number of methylamphetamine interdictions increased more than 12-fold from 88 in 2009-10, to 1084 in 2012-13. The weight of the drug seized similarly increased from $160 \mathrm{~kg}$ in 2011-12 to almost 1.5 tonnes in $2012-13$. $^{3}$ These data suggest that the problem is demand for drugs; while this demand remains strong, there will always be a supply.

The prevailing theme of the Ice Taskforce report was an emphasis on drug treatment over law enforcement measures as a response to ice use. ${ }^{1}$ While this recommendation came from the whole Taskforce, it reflects the sentiment of the chair, former Victorian Police Commissioner, Ken Lay. Many others, including serving and retired senior police, are now coming forward to argue that Australia cannot arrest and imprison its way out of its illicit drug problem.

\section{Matthew Y Frei}

Alex D Wodak

1 Turning Point Eastern Health Melbourne, VIC.

2 Alcohol and Drug Service, St Vincent's Hospital,

Sydney, NSW.

matthew.frei@ easternhealth. org.au
The limitations of a reliance on attempts to restrict drug supply are well recognised. More than a quarter of a century ago, an Australian parliamentary committee concluded:

Over the past two decades in Australia we have devoted increased resources to drug law enforcement, we have increased the penalties for drug trafficking and we have accepted increasing inroads on our civil liberties as part of the battle to curb the drug trade. All the evidence shows, however, not only that our law enforcement agencies have not succeeded in preventing the supply of illegal drugs to Australian markets but

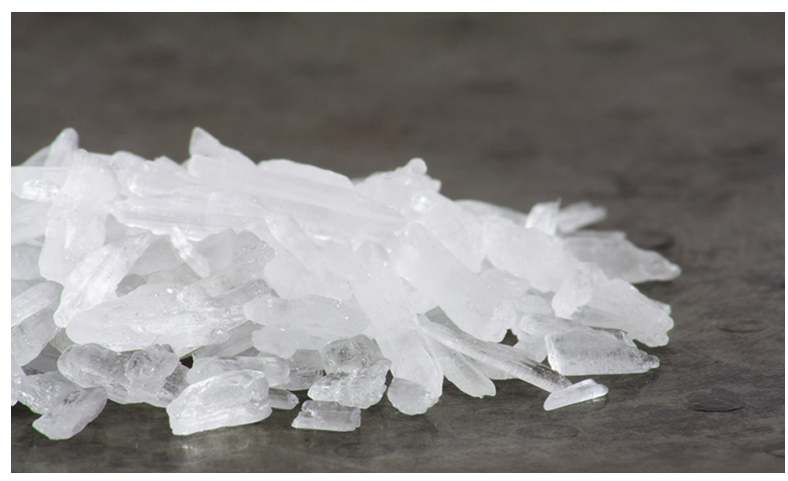

But to date, governments continue to define the issue as primarily a criminal justice problem, use pejorative terms when referring to people who use drugs, and generously support law enforcement measures while parsimoniously funding health and social interventions.

Australian Commonwealth, state and territory governments allocated about two-thirds of drug spending to law enforcement and only 9\% for prevention, $21 \%$ for drug treatment and $2 \%$ to harm reduction over the 2009-10 financial year. ${ }^{5}$ After decades of this approach, Australia's illicit drug market is expanding. Not only are illicit drugs easy to obtain but prices have fallen and many newly identified psychoactive drugs have appeared, often more dangerous than older drugs. Over recent decades, drug-related deaths, disease, crime, corruption and violence appear to have increased. ${ }^{6}$

Harsh approaches are not just ineffective, they are often counter-productive. When access to treatment and sterile needles and syringes were restricted in some countries, HIV prevalence increased among people who inject drugs. ${ }^{7}$ Prohibition of botanical cannabis and other drugs has paved the way for a thriving industry in synthetic analogues. ${ }^{8}$ In Australia over recent years, crystalline methylamphetamine dominates the market over less potent powder forms of the drug or speed. Vast sums largely spent on criminal justice measures have only succeeded in making a bad drug problem much worse.

In Australia and other countries, research into medication-assisted treatment of psychostimulant use problems is limited to a handful of reports, mostly with small sample sizes. ${ }^{10}$ Large scale studies of methamphetamine pharmacotherapies in combination with psychosocial support are needed. Substitution therapy has been remarkably successful for people dependent on opioids, particularly those who have not benefitted from first line psychosocial interventions. ${ }^{11}$ Methadone, buprenorphine and heroin-assisted treatments are backed up by compelling evidence of efficacy, safety and cost effectiveness. ${ }^{11}$ Over the 1990 s, 
Switzerland expanded and improved its approach to drug addiction, including adding drug consumption rooms and heroin-assisted treatment as options for reducing injection drug-related harm. ${ }^{12}$ Treatmentresponse capacity that emphasised social reintegration was increased. As a result of this approach, Zurich saw a drop in numbers of new heroin users (from 850 to 150) by 2002, as well as fewer drug overdose deaths, less crime, low numbers of new HIV infections among people who inject drugs, and a decline in the quantity of heroin seized. ${ }^{12}$ While there are limited subsequent data on numbers of new heroin injectors in Zurich, the average age of drug users in treatment continues to increase, suggesting that initiation of new, younger users is remaining low.

A minority of drug users who have proved refractory to treatment often account for a disproportionate share of community harm and also contribute significantly to the recruitment of new users. ${ }^{13}$ Optimising treatment delivery to this severely dependent group of "super consumers" has the potential to significantly reduce the magnitude of drug-related harm. Attracting and maintaining severely dependent and treatment-refractory users in alcohol and other drug therapy programs would be expected to reduce the size and demand of the market for ice. To date, there has been little research into effective stimulant agonist substitution therapies akin to methadone for heroin users. It is therefore encouraging that an Australian trial will evaluate lisdexamfetamine, an agent that, due to the addition of lysine, is inert if injected and has a longer half-life than oral dexamphetamine. ${ }^{14}$ Other medications such as modafinil, bupropion, oral naltrexone and $\mathrm{N}$-acetylcysteine also deserve further investigation, given the impact of ice and the paucity of existing pharmacological options.

While the Ice Taskforce acknowledgement of the role of treatment is positive, it follows years of parsimonious funding for drug treatment that has left Australia with an inflexible, poor quality system with limited capacity. This would not be considered acceptable anywhere else in the health sector. The funding earmarked for Primary Health Networks as an outcome of the Taskforce is welcomed, but it is unclear whether this will be distributed effectively given the fragmented nature of Australian drug treatment systems. An encouraging aspect of the Taskforce recommendations was the provision of Medicare item numbers for the relatively new discipline of addiction medicine. This was implemented in November 2016, ${ }^{1}$ ending many years of struggle for this important specialty. Suitable item numbers will help addiction medicine recruit new trainees and build a specialist alcohol and other drug sector.

The Taskforce recommendations emphasise that drug education must be based on evidence. Government and the community often have unrealistic expectations of drug education's potential to reduce demand. In fact, gains from conventional drug education are generally modest and often only temporary. ${ }^{15}$ At worst, drug education may actually increase demand and too often ends up in embarrassment like the recent New South Wales anti-cannabis "Stoner Sloth" campaign, which attracted considerable ridicule. ${ }^{16}$ Drug education must be credible for the target audience, which is hard to achieve in an environment of drug prohibition.

Redefining drug use as a health and social issue within a harm reduction framework will require progressive policy. Consideration needs to be given to supervised consumption facilities in major drug "hot spots". Drug consumption rooms have the potential to offer information about harm reduction and treatment, to decrease the risk of overdose and other drug-related morbidity, and to reduce the negative impact on neighbourhood amenity. Just as we support needle syringe programs, we need to evaluate the provision of ice using equipment (such as glass pipes to attract and accommodate the significant proportion of marginalised users who inhale rather than inject methamphetamine) and encourage more disaffected ice users to seek health and social assistance.

Although there is considerable community concern about ice, any discussion of illicit drugs needs to be put into perspective. The public health burden from crystalline methylamphetamine is still dwarfed by our favourite intoxicant, alcohol, and by tobacco. ${ }^{17}$ Pharmaceutical opioid and benzodiazepine dependence also continue to contribute to the morbidity and mortality of Australians while these drugs are too often prescribed indiscriminately. ${ }^{18}$

British politician Denis Healey was fond of saying "if you find yourself in a hole, stop digging". It's time Australia took his advice when responding to illicit drugs.

Competing interests: No relevant disclosures.

Provenance: Not commissioned; externally peer reviewed.

(c) 2017 AMPCo Pty Ltd. Produced with Elsevier B.V. All rights reserved.

References are available online at www.mja.com.au. 
1 Department of the Prime Minister and Cabinet. Final report of the National Ice Taskforce. Canberra: Commonwealth of Australia, 2015. https://www. dpmc.gov.au/sites/default/files/publications/national_ice_taskforce_final_ report.pdf (accessed Dec 2016).

2 Prime Minister of Australia, The Hon Malcolm Turnbull MP. A new action plan to tackle ice [media release]. 6 December 2015. https://www.pm.gov. au/media/2015-12-06/new-action-plan-tackle-ice (accessed Dec 2016).

3 Stafford J, Burns L. Key findings from the 2014 Illicit Drug Reporting System. Proceedings of the 2014 National Drug Trends Conference; 20 Oct; Sydney, Australia. https://ndarc.med.unsw.edu.au/sites/default/files/newsevents/ events/Presentation\%20-\%20Jenny\%20Stafford\%20-\%20IDRS\% 20National\%202014.pdf (accessed Dec 2016).

4 Parliamentary Joint Committee on the National Crime Authority. Drugs, crime and society. Canberra: Australian Government Publishing Service, 1989. http://www.aph.gov.au/parliamentary_business/committees/house_of_ representatives_committees?url=report_register/bycomlist.asp?id=176 (accessed Dec 2016).

5 Wodak A. The abject failure of drug prohibition. Aust N Z J Criminol 2014; 47: 190-201.

6 Ritter A, McLeod R, Shanahan M. Government drug policy expenditure in Australia - 2009/10. (Drug Policy Modelling Program Monograph No. 24). Sydney: National Drug and Alcohol Research Centre, 2013. https://ndarc. med.unsw.edu.au/resource/24-government-drug-policy-expenditureaustralia-200910 (accessed Dec 2016).

7 Csete J, Kamarulzaman A, Kazatchkine M, et al. Public health and international drug policy. Lancet 2016; 387: 1427-1480.

8 Banister S, McGregor I, Gerona R. Labs make new, dangerous synthetic cannabinoid drugs faster than we can ban them. The Conversation 2015; Nov 5. https://theconversation.com/labs-make-new-dangerous-syntheticcannabinoid-drugs-faster-than-we-can-ban-them-47896 (accessed Dec 2016).

9 Australian Criminal Intelligence Commission. Amphetamine-type stimulants. Illicit Drug Data Report 2014-15. Canberra: ACIC, 2016. https://www.acic.gov. au/sites/g/files/net1491/f/2016/08/02-amphetaminetypestimulants-aciciddr-2014-15.pdf? $v=1470179432$ (accessed Dec 2016).

10 Lee $\mathrm{N}$, Jenner L. Medication treatment options for amphetamine-type stimulant users (ANCD Research Paper No. 29). Canberra: Australian National Council on Drugs, 2014. http://www.atoda.org.au/wp-content/ uploads/rp29-medication-treatment-options.pdf (accessed Dec 2016).

11 Strang J, Groshkova T, Uchtenhagen A, et al. Heroin on trial: systematic review and meta-analysis of randomised trials of diamorphine-prescribing as treatment for refractory heroin addiction. Br J Psychiatry 2015; 207: 5-14.

12 Nordt C, Stohler R. Incidence of heroin use in Zurich, Switzerland: a treatment case register analysis. Lancet 2006; 367: 1830-1834.

13 Prime Minister's Strategy Unit. Strategy Unit Drugs Report. Phase one Understanding the issues. London: Cabinet Office, 2003. http://webarchive. nationalarchives.gov.uk/+/http:/www.cabinetoffice.gov.uk/media/ cabinetoffice/strategy/assets/drugs_report.pdf (accessed Dec 2016).

14 Jasinski D. Krishnan S. Abuse liability and safety of oral lisdexamfetamine dimesylate in individuals with a history of stimulant abuse. J Psychopharmacol 2009; 23: 419-427.

15 Hawthorne G. Drug education: myth or reality? Drug Alcohol Rev 2001; 20: $111-119$.

16 Arlington K. NSW Government's Stoner Sloth anti-marijuana campaign cost taxpayers $\$ 350,000$. Sydney Morning Herald 2016; 19 Feb. http://www.smh. com.au/nsw/nsw-governments-stoner-sloth-antimarijuana-campaign-costtaxpayers-350000-20160218-gmxd8p.html (accessed Dec 2016).

17 Collins DJ, Lapsley H. The costs of tobacco, alcohol and illicit drug abuse to Australian society in 2004/05. Canberra: Commonwealth of Australia, 2008. http://www.health.gov.au/internet/drugstrategy/publishing.nsf/Content/ 34F55AF632F67B70CA2573F60005D42B/\$File/mono64.pdf (accessed Aug 2016).

18 Roxburgh A, Bruno R, Larance B, Burns L. Prescription of opioid analgesics and related harms in Australia. Med J Aust 2011; 195: 280-284. https://www. mja.com.au/journal/2011/195/5/prescription-opioid-analgesics-and-relatedharms-australia 